\title{
CONSTRUCCIÓN DE LA REALIDAD POETTICA: EL POETA COMO PERSONAJE Y LA REALIDAD COMO FICCIÓN: LUIS A. DE VILLENA.
}

\author{
Osvaldo Picardo \\ Universidad Nacional del Mar del Plata. Buenos Aires. Argentina.
}

\section{I.-IMAGEN TEXTUAL E IMAGEN SOCIAL DEL POETA.}

Noticia preliminar sobre la obra de L. A. de Villena.

Luis Antonio de Villena nace en Madrid en 1951. Se licencia en Filología Románica en 1973. Después de un breve tránsito por la docencia, se dedica plenamente a la literatura. Francisco Brines ha dicho que en él "se muestran dos faces tan verdaderas como, en ocasiones, contradictorias entre sí: me refiero a la que nos descubre su persona y la que nos manifiesta su personaje".

La función extraliteraria de su poesía está presente a cada momento. Citando a Walter Mignolo, podemos decir que en Villena "la imagen textual del poeta tiende a confundirse con la imagen social del mismo". El poeta madrileño parece moverse en ese umbral delgado, cayendo a uno u otro lado a lo largo de su obra y construyendo desde allí una equívoca lectura de la figura del poeta/autor.

Esta obra que va desde el esteticismo a ultranza de los primeros novisimos hasta un realismo vitalista, da comienzo con la antología de Antonio Prieto, prologada por Vicente Aleixandre, Espejo del Amor y de la Muerte (1971). Prosigue en libros como Sublime Solarium (1971); Hymnica (1era.ed., 1979); El viaje a Bizancio (1976); Hymnica (ed. definitiva 1979); Huir del Invierno (1981) que obtuvo el Premio de la Crítica de ese año; La 
Muerte Unicamente (1984); Como a Lugar Extraño (1990) que marca la transición a su último libro, Marginados (1993), con el que pone el acento sobre una lengua poética que hace rever toda anterior apreciación. Autor también de ensayos y ediciones críticas : Introducción al Dandysmo (1974); Antología general e Introducción a la obra de Manuel Mujica Lainez (1976); Dados, amor y clérigos (1978); Catulo (1979) y Oscar Wilde (1979) entre otras obras. Ha publicado un libro de cuentos, Para los Dioses Turcos (1980) y entre sus novelas , Ante el Espejo (1982) y Chicos (1988). Y sus dos últimas obras El Tártaro de las Estrellas (1994) y El Burdel de Lord Byron (1995), con el que obtiene el premio Azorín de novela.

\section{II.-SISTEMA LITERARIO DESDE LOS '70 HASTA LA PUBLICACION DE MARGINADOS.}

\section{II.1.-Introducción teórica: Hacia un nuevo pacto de lectura de la poesía.}

Para el presente trabajo he debido recurrir a una serie de nociones teóricas que permitieran desarrollar la tesis del mismo: la institucionalización en el sistema literario español de una relación contractual entre autor y lector, relación a través de la cual se posibilita un cierto realismo en el programa escritural villeniano, que abarca la curva lírica 1971-1993. Ese diálogo implícito entre autor y lector, diálogo ilusorio en que las ausencias textuales de sus interlocutores marcan un modelo de escritura, es la motivación central del presente trabajo. Por eso, acto seguido, deberé precisar algunos conceptos teóricos utilizados para este fin.

Un concepto fundamental que deriva de Tinianov (en La nocion de construcción y en Sobre la evolución literaria), además del de función y principio constructivo, es el de sistema. El concebir a la literatura como sistema viene a reemplazar los anteriores conceptos de "época" o "período". La literatura concebida como sistema se puede definir así: como un espacio productivo y no como un depósito de obras; es el conjunto de posibilidades para la producción y la lectura de una obra literaria. Es un estado de la literatura. De ahí que en un sistema existan poéticas dominantes, emergentes y residuales que delimitadas por factores extraliterarios actúan como fuerzas microfísicas de esos mundos posibles. Por ejemplo, en el sistema literario español de mediados de siglo XX, la poética dominante es la poesía social, la emergente es la poética de los novísimos, las residuales son aquellas constituidas en un pasado que cobran, sin embargo, funcionalidad en el presente, por ejemplo: el surrealismo, el postismo, etc. 
La literatura puede ser entendida como serie o sistema mientras que la obra literaria, también puede verse como sistema. Así se puede hablar del sistema literario de un autor determinado y también de una corriente literaria como sistema. Por eso es necesario ver la obra de Villena en una curva lírica sobreimpresa a la estética novísima y a la poesía de los ' 80 , y en ello, las correlaciones de lo literario y de lo extraliterario. Entre lo extraliterario, la prensa periódica y los mass media ofrecen un una versión de segundo grado del sistema literario legitimado por la cultura letrada, y es así como el manejo de los mass media impone modelos y paradigmas condicionantes de los programas de escritura de un autor. El caso de Villena resulta, en esto, sumamente interesante, porque su personaje social — como lo marcaba Brines- se imbrica con sus otros sujetos textuales, ante un gran público, ya sea desde la televisión o desde la columna periodística.

La construcción de la representación de la figura del autor, en su doble rol (social y literario), tiene en Villena - como ya queda dicho- una importancia significativa a la hora de explicar la curva lírica de su poesía. En cuanto a la representación del yo en la poesía de Villena, son evidentes las referencias al cuerpo y a su locación en el espacio, como materialización de una presencia del yo autobiográfico o de ego mentior en la constitución de una erótica homosexual. El enmascaramiento cultural, unas veces, y coloquial, otras, muestran una búsqueda del sujeto como objeto, cuya función, si bien es la "volatilización" de la figura del poeta, no se cumple en Villena sino que todo proceso de objetivación redunda en constitución de contornos y reafirmación de su figura. La fusión entre el polo del sujeto y el polo del objeto se da principalmente en la construcción casi objetiva de la realidad marginal, ya sea ésta entendida como socialmente periférica o estetizada por el deseo y desplazada u opuesta al mundo. Por otro lado, los metatextos están presentes en la obra villeniana - también en los paratextos de sus libros de poemas-, evidenciando la necesidad de explicar la actividad poética propia y de la época. En cuanto a la práctica significante dentro de la praxis social, ha sido entendida por Villena de una manera particular, que ha ido articulando a otras prácticas en una intensa vida social y pública. No podemos decir que en este poeta haya un "proceso impersonal" como lo intentaban Carnero o Talens, porque su obra es fuertemente de ficción biográfica; no obstante sí es posible entender al autor una manera "espacial" de distancias y proximidades, como un "lugar no fijo" desde donde se habla, se organiza un mundo, se le da coherencia experiencial, y se sistematiza lo extrasistemático - como es el caso del sermo urbanus en Marginados. 


\section{III.-LA POESIA DE VILLENA: DESDE EL GRAN ESTILO AL REALISMO.}

La constitución de un sistema literario dominante desde los '70, conllevó, en España, diversidad de opiniones y multitud de publicaciones, entre ellas, las antologías. Esta estrategia antológica que se instituye en la poesía española, con Gerardo Diego y su famosísima antología, obtuvo en los $70 \mathrm{su}$ época de plenitud. García Martín (1980) considera a los poetas del setenta como "una generación en seis antologías": la de Castellet (1970), la de Martín Pardo -que, como ya hemos visto, había publicado otra con anterioridad a 1970 - la de Prieto (1971), la de Batllo (1974), la de Pozanco (1976) y la de G.Moral y Pereda (1979). Este ritmo de publicaciones antológicas a lo largo de una década puede muy bien ordenar y delimitar con mayor claridad el fenómeno de la poesía "novísima", aunque difícilmente resuelva las contradicciones de un mosaico tan heterogéneo de personalidades que van desde Carnero a Villena, de un Leopoldo Ma. Panero a Luis Alberto de Cuenca y de Gimferrer a Ullán, por mencionar algunos.

En este cuadro editorialista en el que caben no sólo los poemas antologados sino los intereses e ideologías de una época histórica de España, representación aproximada, aunque inexacta, de todo un sistema literario y social en los '70, podemos ubicar a Luis Antonio de Villena en la publicación de Antonio Prieto -El espejo del amor y de la muerte, así se llamó esta desafortunada publicación, que reunía entre otros a Javier Lostalé, Luis Alberto de Cuenca y Luis Antonio de Villena-, donde "el culturalismo - dice García Martín - de estos poetas será (en comparación al "farragoso prólogo" de Prieto) igualmente afectado hasta el extremo".

Esta categoría de no incluidos en la antología de Castellet o de Pardo, refleja una suerte de subclasificación cuyas características oscilan entre las del centro y las de la periferia de la estética dominante, exagerando en ocasiones los rasgos en función de una identificación generacional y escapando, en otras ocasiones, de los mismos hacia estéticas desplazadas. El caso de Lostalé, por ejemplo, que sigue una línea menos novedosa en que se revela la continuidad de los hallazgos de Francisco Brines, figura que representa en Villena una fuerte influencia para su posterior obra. Esta circunstancia — si bien los sateliza - los deja - mucho antes de la crisis de los novísimos que se produjo entre los años 1973-1977- en una posición menos restringida por las leyes operativas del sistema literario, y les posibilita —en el caso de Villenaabrirse hacia otras posturas éticas ante la lengua y la sociedad, y divergentes problemáticas estéticas en la construcción de un discurso de la propia subjetividad, hasta el punto de dar un giro de $180^{\circ}$ hacia el realismo. 
El sistema literario y cultural de la España anterior a los del '70, inscribía, hegemónica, una estética realista - con sus muchas variantes-, y libros como Señas de identidad de J. Goytisolo - junto a sus ensayos-, como La inspiración y el estilo de Juan Benet y como el prólogo de Castellet a la antología de los novísimos, constituyeron un verdadero asalto al poder desde una estética que respondía a los cánones de un simbolismo formalista, cargado de las teorías lingüísticas de la época que ponían en crisis la referencialidad del lenguaje. Se consolida de este modo un rechazo explícito - literario y teórico - al realismo. Es, por un lado, Benet el que en el ya mencionado libro de ensayos, afirma que el poeta es el un hombre "que reclama todo del estilo y nada de la ciencia del significado"; y, por otro lado, es Goytisolo el que anuncia que "las palabras no son los dóciles nombres de las cosas", y que el discurso viene a ser más importante que la historia, distinción de Benveniste', que Goytisolo aplica al rescate de una obra como Tiempo de silencio, de Martín Santos, porque en ella se disuelve "el relato en el murmullo de su propio discurso".

Resumiendo la postura de Lanz $(1994)^{2}$, entiendo que el sistema cultural de este período inmiscuye los hechos políticos en los culturales, bajo el modelo idealizado de la II República y de los paradigmas de la llamada generación del '27, modelo político, estético y social construido dentro de la cultura franquista, y cuya emersión en España produce un salto por encima de 40 años de dictadura. En esta sincronía, la convivencia de los novísimos y de los poetas postfranquistas deriva en una poética del silencio o en la "poesía de la experiencia figurada" ${ }^{3}$ en cuya raíz germina la experiencia profunda de una España en tránsito hacia el modelo democrático europeo,neo capitalista. El proceso de cambio de Villena, acompañado de una práctica artística que ha ido forjando su imagen social, se inserta en este sistema cultural y opera desde él en el momento de la escritura.

\section{III.1.-Hilos poéticos. (Hacia una intertextualidad del modelo.)}

En el "Epílogo" de Marginados, Villena propone una orientación para entender el cambio que este libro acusa en su poesía, aunque él mismo se cuide de decir que en el curso de su poesía "estos poemas son un aparte (relativo)". Escribe: "A fines de junio de 1989, recogiendo - me parece- hilos poéticos que venían de muchos años atrás (véase en Hymnica, "Salud a todos al empezar un año", poema escrito en enero de 1976) me vi tratando de acercarme a una grimosa realidad, que es imposible no ver, y que siento, a la par, terrible y lírica. Me vi ante un poema social, neosocial, urbano, da lo mismo. 
Quería ser objetivo, no íntimo. Pero todo se llenaba de fisuras - sino personales-cálidas".[ p.53 ] El poema, al que se refiere, dice:

Son las horas inciertas de la madrugada.

Los andenes del metro, con el nuevo año,

llevan restos de confetti y brillos. Cristales

rotos y una mugre extraña con perlas, saliva

y vino. Ellas arrastran los cansados trajes

de una fiesta, y procuran que no sufra

más dafios el rostro, en el que quedan aún

desvaídas islas de maquillaje. Unos ríen

con risa tarda y dormitan otros sobre

asientos de madera. Confetti, brillos, manchas, y algún antifaz radiante.

Solo, y de regreso, lo miro todo con

el placer extraño de una participación

indiferente. $Y$ observando una hermosura

que se acoge a una bufanda, pienso

en la espléndida desnudez que muy pronto

será en un cuarto pequeño. Y me veo a mí,

solo. Y sueño en una buena forma de empezar

el año, mientras me acuerdo de detalles

$\mathrm{y}$ amigos, $\mathrm{y}$ saturnales paganas, $\mathrm{y}$ lo miro

todo con curiosa solidaridad y más

curiosa distancia. Todo, menos el cuerpo

hermoso. Y el metro traquetea muy cansado.

Son las horas inciertas de la madrugada.

Esta otra realidad constituye una imagen y actitud recurrentes en el sujeto, un "hilo poético", una relación intertextual, lo que supone la continuidad e insistencia de un modelo o proyecto de escritura, en la obra de Villena, y que se va reconociendo o leyendo a medida que se configura el corpus textual como tal. La apropiación de este modelo cultural constituye la creación de un discurso propio, en el que la construcción de orra realidad como objeto comporta también la construcción de un sujeto. Pero veremos cómo este modelo cultural de Villena se diferencia del sistema estético de la época novisima, avanzando sobre la referencialidad del discurso.

Ya en "Raso en la autopista", poema de Sublime Solarium, la otra realidad tiene lugar. La escenografla del metro de Madrid, en ocasión del año nuevo, es el continente de un estado de soledad del que regresa y en el que se manifiesta un principio constructor nuevo: "solo, y de regreso, lo miro 


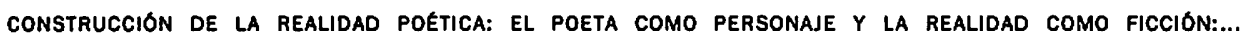

todo con/ el placer extraño de una participación/ indiferente". Y más adelante :"y lo miro /todo con curiosa solidaridad y más/ curiosa distancia.Todo menos el cuerpo/ hermoso." Si bien aún está presente el deseo idealista de corporalizar la belleza, esa rara lectura que hace Villena de Wallace Stevens en Viaje a Bizancio, cuando escribía que "la alegría de la posesión [es] nuestro único objeto" ", en este otro poema se abre una percepción del mundo distinta, donde las referencias "a una grimosa realidad" emergen aunque anteriores todavía a la modulación de las voces y el ocultamiento de un sujeto poético en el "sermo urbanus". Estas dos dimensiones, grimosa realidad y sermo urbanus, son, en síntesis apretada, pilares de la construcción del mundo poético en que Villena había soslayado la mirada, pero sin entrar. Esta escenografía urbana y contemporánea de lo marginado en que se incluye la homosexualidad y su mundo entre clandestino y desafiantemente escandaloso, constituye un proceso de asimilación e incorporación poética de nuevos correlatos objetivos tales como los que se ofrecen en otros poemas de Hymnica y que enhebra el mismo "hilo poético". Me refiero a "Homenaje a Catulo de Verona", "Para honrar a Ibn Quzman, Zejelero", "Historia de madrugada", "Iluminación (con leve retórica) en una discoteca", "El reino de este mundo" y en menor medida, "Continuación de una vida".

Señala García Martín que "el aspecto más original de Hymnica es el que preludia la posterior obra narrativa del autor y que podríamos calificar de novelesco" (op. cit., 1992, pág. 146). Con esta modalización de la enunciación, Villena se ubica en las antípodas de su primer libro e inicia una construcción de la realidad y de un sujeto, que la percibe y se percibe en el texto, cada vez más próximo a la "poesía de la experiencia" de la segunda generación de posguerra, la de un Francisco Brines o un Jaime Gil de Biedma. El hecho de penetrar en el realismo para un poeta que proviene del idealismo platónico por un lado, y del venecianismo novísimo por otro, exige a su práctica artística una fuerte voluntad para estar presente en la vida social y gran versatilidad en la escritura. Comporta la gestualidad de una imagen propia que coincide, en gran medida, con una especie de marginalidad disidente, heterodoxa y renovadora. Especie de marginalidad, que no obstante constituye, una centralidad cultural y social, muchas veces legitimada sin obstáculos, tanto en la prensa como en los otros mass media, que explotan sus aspectos espectaculares más que sus aportaciones distintivas y enriquecedoras, según una institucionalizada representación de la poesía.

En cuanto al texto poético, éste se transforma en un enunciado performativo, como sucedía en la ficción autobiográfica de la poesía de Gil de Biedma, donde la función poética la constituye el hacer una persona. En el mismo libro de poemas, Hymnica, se halla "La vida escandalosa de Luis 
Antonio de Villena", que podemos leerlo como ejemplificación de esta intencionalidad performativa:

¿Y qué puedo decir? ¿Asentir? ¿Negarlo?

He bajado las escaleras que he bajado

(muy en penumbra, a menudo), me he tendido

con los cuerpos que han sido - con esos precisamente-

aunque no, desde luego, con cuantos he deseado.

Con la vista me voy, sin evitar atajos,

a los lugares aquellos que no sospecha nadie.

A ciertas horas no se llame a mi teléfono;

donde voy aquel rato no lo nombro al amigo

-ese que tiene casa y mujer y empleo asegurado-.

Lo que bebo en tu copa (he hablado de ti

todo el poema) lo adjetivo para que no se entienda.

Lo que hago contigo lo niega mi faz por la mañana.

Por la esquina maleva paso, embozado, muchas noches.

¿Asentir? ¿Negar? Sé bien que se murmura.

Pero yo no hago caso. ( $\mathrm{Y}$ no se escandalicen los prudentes).

Que toda vida que se vive plena es vida para escándalo.

A partir de este texto, se homologa autor con emisor. En las poéticas sociales o testimoniales, anteriores al ' 70 , era frecuente el recurso del correlato autoral, semiotización biográfica con la que se buscaba el efecto de verosimilitud e historicidad, acentuando la ilusión referencial del discurso. El modelo o proyecto de escritura de Villena se materializa entonces, con un nuevo pacto de lectura. No sólo construye discursivamente un sujeto sino que también un lector.

\section{III.2.-Las extraniezas del sujeto y el mundo.}

En Como lugar extrańo (1990) es una recopilación de poemas escritos entre 1985 y 1989, y marcan otra instancia de su itinerario poético, un tránsito hacia Marginados. Su novela Chicos (1989) está en íntima relación con la escritura de este libro. Esto se ve en poemas como " $\mathrm{El}$ joven de los pendientes de plata" o "Hermosos rostros del pasado".

El tránsito al que me refiero, establece la construcción de un sujeto cronista de un mundo "de noches locas y chulitos espléndidos". Logra, por lo tanto, un distanciamiento en el que gravita el sentimiento de extrañeza del mundo, extrañeza o extrañamiento que Luis Antonio de Villena define en el "Liminar" del libro: 
"El mundo, la vida, es para nosotros un lugar extraño, porque existen imposibilidad y dolor, y entonces el deseo, la perfección, el anhelo de belleza, quedan, casi permanentemente, ajenos. Mas hay lugares extraños en el lugar extraño: el erotismo, la felicidad de la vida como vida sentida, las extranas ínsulas del júbilo, ese gozo de la carne psíquica son asimismo lugares extraños. Y cuando desatendemos la vanidad, cuando intentamos salir de nosotros...estamos nuevamente en otro lugar extraño " (pág. 7).

La identificación con el "nosotros", en este paratexto, delimita otro lugar de la enunciación, que se autoexcluye de lo convencionalizado social y culturalmente como moral, cristiano y natural. Preludia, de este modo, a Marginados, que, por cierto, connota per se una espacialidad significativa y significante, en coincidencia con esta extrañeza del sujeto que intenta "salir" de sí y ser un cronista del nosotros. Lo preformativo autobiográfico no se disuelve, sino que se acentúa, desde otra actitud, mostrando su contexto - el yo en el nosotros de pertenencia - y volcándose a la exploración de lo real contemporáneo en el cuadro de costumbre, en lo histórico, poeticidad de lo marginal, etc. La construcción del mundo villeniano es, ahora, más la labor de una arqueólogo del mobiliario social y axiológico, que la de un coleccionista de la belleza ideal o estética.

\section{III.3.-Los deplorata silentia y la antiliteratura.}

Con el acostumbrado intento de explicarse, al empezar o terminar un libro, Villena escribe en el Epílogo de Marginados:

"Estos Marginados lo son de veras. Los de siempre. Todo lo que amo y detesto. Lo que me refleja y - otras veces- me parece intolerable. Hay en estos Marginados piedad (¿por qué temer la palabra?) pero también celebración, apetito de vida. Detrás de toda marginación hay pasión, si delante es más que visible la injusticia. Pasolini escribió en carta a su amigo Spagnoletti (era en los ańos cincuenta): Cuando de la vida se ha consumido todo, aún queda todo. Por eso he hablado de celebración".

Por un lado, esta explicación paratextual de Villena, puesta al final del libro para que el lector alcance la posibilidad del archilector, que se alce con el acierto de un significado ideal, dice más de un "sí mismo" construido socialmente como el poeta Luis Antonio de Villena, que de los poemas que lo anteceden. No quiero decir que sus aclaraciones están de más, ni que no sirven a la hora de interpretar la experiencia de la lectura, sino que denuncian, una vez más - hay paratextos explicativos en casi todos los libros de Villena-, la voluntad escritural de fusionar el rol social con el rol textual, de dejar libre la natural tendencia del consumidor de libros a identificar al suje- 
to con el poeta, pactando la lectura en la ilusión realista. Por eso explica: "Nadie soy yo en estos poemas, pero me siento algo en todos ¿Se podría escribir de otra manera? Es poesía social o poesía de la pena, la rabia, la pasión y el desprecio: Móviles de vida".

Por otro lado, en estas palabras epilogales se ratifica lo evidente de los personajes, "dioses menores" en Como a lugar extraño, evidente en la cita de Apuleyo sobre los silencios deplorados de los de abajo, en las prosografías y etopeyas, en los cuadros de costumbres y en los testimonios que, ya sea en una tercera o primera persona, se nos van presentando en los veintidós poemas que componen el libro. La construcción de estos personajes, es también la construcción de una experiencia del sujeto de la enunciación, de sus márgenes y de su silencio no deplorado. El privilegio de un pathos - una forma de apasionarse con el mundo representado - y un ethos - una forma de mostrarse ante el mundo que va representando- son recurrencias de sus otros libros, que aquí se resuelven en un proyecto de escritura realista.

El itinerario lírico de Villena puede graficarse como la curva de un "hilo poético" en que concurren varios elementos:

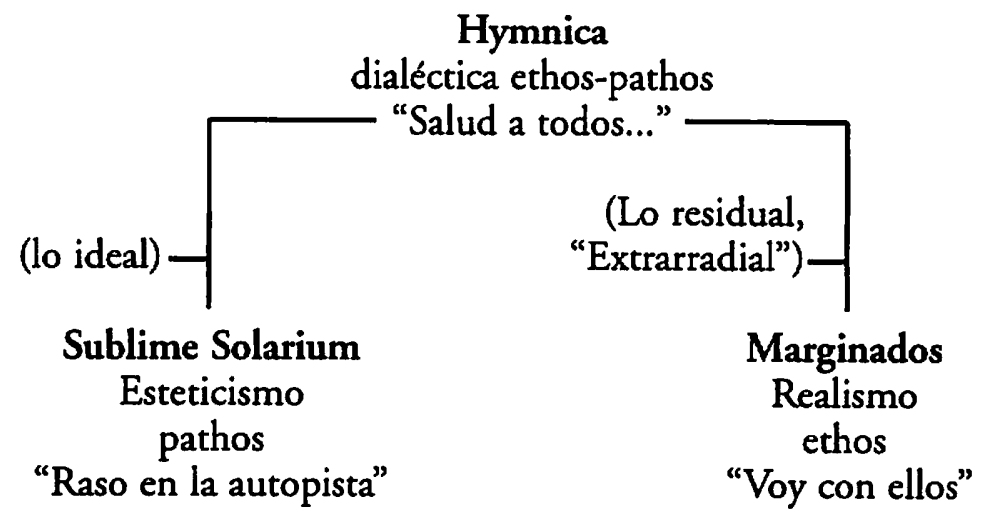

J. O. Jiménez (op. cit. págs. 13-14) habla de tres estadios poéticos en la poesía de Villena: a) Sublime Solarium (1971) — modulación de un lenguaje y de la temática de la belleza-; b) El Viaje a Bizancio (en su versión definitiva de 1978) - construcción mítica de un mundo propio tematizando belleza y deseo-; y c) Hymnica (1979) y Huir del Invierno (1981) -integración de la voz y del mundo. Sin embargo, esta división corresponde a una época anterior a sus dos últimos libros y podemos reducirla, en base a esa curva lírica hasta 1993, año de publicación de Marginados, en dos momentos: 
a) el que corresponde a la estética "rupturista" de los novísimos (que incluye el venecianismo primero y el alejandrinismo después), y que incluye sus obras hasta el período de 1974-1980, período de transición que irá evolucionando hacia una mayor aproximación a la realidad y un tono elegíaco narrativo que a veces se resuelve en lo epigramático, el libro en que mejor se expresa esta transición es Como a Lugar Extraño (1985-1989);

b) y el que corresponde a una nueva estética expresada en Marginados (1989-1993).

La gran innovación consiste aquí en el lenguaje - "la pasión de este libro es el lenguaje y las voces varias" - y la estrategia con que se posiciona el sujeto en los actos de habla; es decir, la instancia de la enunciación y los turn ancillaries, las estrategias primordialmente narrativas de las que se vale el sujeto de la enunciación para ceder la voz a sus personajes. Es ahí donde Villena intenta ser nadie en los poemas, aunque se sienta - como el sujeto de "El Antiguo"- "algo en todos".

"Voy con ellos" es el poema proemio en que el sujeto desaparece en el "ellos". Recorre una serie etográfica de personajes rápidamente apuntados. Todos son mostrados en un movimiento de concentración, vienen desde los márgenes hacia un espacio que hacia el final del poema se desvela como "un salón vacío con el suelo de mármol", y que es puesto en relación semántica con la imagen desconsolada de la tumba, un verso antes de finalizar. El efecto de multitud acumulativo de la enumeración y del polisíndeton alcanzan, con un verso cercano a la prosa, un ritmo lírico ascendente que culmina en otra acumulación: la que intenta determinar el espacio de reunión y "la ausencia de voz". Esta intensificación lírica, que lamentablemente es desbordada por los últimos versos en que las preguntas no agregan nada a lo ya dicho y desmerecen el poema, circunscriben un centro significativo:

"a un hueco que les han dejado ahora, en este solo instante, y ante el gran silencio, ante el vacío, ante la ausencia de voz, ante la nada retumbante y repetida..."

El silencio definido como "ausencia de voz" coincide con este desplazamiento del sujeto textual, que abandona el lugar del yo del enunciado y se pronuncia desde otro lugar, el "ellos". Esta coincidencia intencional de la enunciación es una estrategia escritural que se inscribe en la línea del "realismo", dejando ver el vacío existencial entre el lenguaje y la realidad, pero que llenará de voces en los otros poemas, para que en su lengua ilegítima, antiliteraria, aparezcan dibujadas las caras sociales del fracaso de la realidad, del ser residual de la época. Esto se expresa, en el epílogo, como "hacer arte del coloquialismo", como tentación del "placer de lo cotidiano sórdido, de la vida 
literalmente hablada" y como "antiliteratura". Hasta qué punto es un mero placer estético o formulación de la poesía social, es difícil delimitarlo.

Aún aceptando que el realismo no se asienta en propiedades formales determinadas (como tampoco ha podido ser aislada la "literariedad" por rasgos de lengua exclusivos), hay formas que favorecen una actualización referencial del texto. D. Villanueva (1989) habla de "repertorio de formas" y entre los rasgos formales y temáticos específicos de ese discurso, menciona la impronta del "no estilo", una lengua limpia y transparente como el vidrio. Estamos con esto en las antípodas de los postulados de Benet. En este último libro de poemas de Luis Antonio de Villena se observa lo que V. Shklovski, en 1929, llamó proceso de singularización aplicado al lenguaje cotidiano, y logrado mediante la descripción del objeto, ya sea un personaje o un escenario como ocurre en el poema "Madrugada en Madrid, agosto, 1990". La cuestión de este proceso realista de singularización es crear una imagen del objeto más que conseguir el efecto de reconocimiento.

Para esto Villena debería recurrir a la opacidad del lenguaje, pero su interés va hacia la transparencia realista del no-estilo, y por eso el léxico y los turnos de habla son los del objeto de la representación.

También la justificación psicológica de la conducta de los personajes, preferentemente simples, y la presencia de nombres actúan como argumentos de autoridad que anclan los poemas en la objetividad y buscan un efecto de realidad.

El poema "Madrugada en Madrid, agosto, 1990" no puede ser más claro en el uso del repertorio de formas realistas, desde la temporalización y la ubicación hasta la tematización de lo residual de la época.

Gran Vía noche arriba, florece la heroína en traje negro.

En las miradas sientes agujas sucias, pensiones de miseria, ojos buscando no sabrías si tumba u otro cuerpo.

Tanta delgadez lunar florece en la Gran Vía, tanto temblor de manos, tanta ruina de infección y hambruna, manchas cutáneas, acaso, sidosos fantasmas que murieron, temor a casi todo, mientras la leche cae del tetrabric abierto, como ese último sueño de aferrarse a una norma... Escuchas pillar algo. Hay un dolor tan denso subiendo la Gran Vía, la enfermedad vagando, aliada del sexo, y aquel muchacho en pantalones cortos, sucios, la chica revestida de huesos esqueléticos, dirías silicóticos peones gaseados. La Gran Vía nocturna es un hondo pasillo de antracita, y hay cuartos por detrás de agonizantes solos, sollozos y rateros. 
Bajo las casas nobles de principio de siglo - polvorientasafricanos y yonquis, navajas, viejas putas, jovencitos oscuros, jeringuillas, travestís y camellos cantan la gloria opaca, la cochambre sin letra de este fin de milenio macilento.

Villena parece partir de la convicción de que la realidad es describible, cognoscible en sus múltiples planos. En esta ilusión referencial de la poesía existe una preocupación epistemológica, donde el mundo posmoderno, filtrado por la cárcel del lenguaje, parece fragmentarse en miles de voces marginales. El canto de "la gloria opaca" es una imagen de ese mundo epocal, como la siguiente: "cochambre sin letra", que lo perspectiviza, expresando desde ese lugar de la mirada, la amarga sensación del fracaso de la realidad.

Por otro lado, el sujeto textual se configura a la manera de poemas anteriores en "La vie est belle", "Tarde de sábado", "Diletante", "Mendigo","Balada de un joven canallita", "Perdido" y "La genovesa". En ellos el sujeto roza lo autobiográfico, en el sentido ya apuntado, y se desprende hacia máscaras que lo incluyen, con mayor o menor acierto, en la polifonía de las voces del corpus. La lectura de Marginados se asemeja a la audición de un coro y un solista. Podemos aplicar lo que Mijail Bajtín señala a propósito del dialogismo: hay una heterofonia (diversidad de voces), una heteroglosia (presencia de distintos niveles de lengua) y una heterología (alternancia de tipos discursivos). Todo lo cual acarrea una multiplicidad de visiones e interpretaciones de la realidad y expresa la conciencia dialéctica de una época.

Son los poemas, en que en mayor grado aparece lo coloquial, los que representan mejor la propuesta de Marginados : "Tigre", "Chapero", "Dama", "Puta vieja" y, sobre todo, "Frívolos". En ellos aparece la transcripción linguística de la jerga y del léxico marginal, instituyendo un discurso de la subjetividad que se opone al convenido o esperado, y, al mismo tiempo, pactando con el lector un nuevo código. Este código implica un cierto realismo tensional en que se juega con el conocimiento que el lector tiene del mundo modelizado, el mundo marginal de Madrid, y con el conocimiento que tiene de la imagen social y literaria del poeta, cuya obra ha decidido comprar en una librería. De hecho, el Villena constructo de su propia poesía -autor implícito - viene a identificarse intencional $e$ intensionalmente con un grupo social; reconociendo un ethos disidente, con anterioridad enmarcado por una erótica de la homosexualidad, el paganismo anticristiano, un idealismo neoplatónico contrapuesto al mundo y el gusto discordante, neobarroco, por lo cultural y lo kitsch. De ahí que su realismo consista en gran 
medida en un pacto que se establece gracias a la modelización de lo que aparece como extrasistemático de la sociedad y del lenguaje poético.

El último poema, "Lobo-hombre", recupera la reflexión sobre el mal que se leía en "Tratado de la única pasión", e intenta inscribir el corpus, en un discurso existencial que sustente una lectura más cercana a la reflexión que a la descripción de la realidad.

Alguien con la boca ensangrentada, pide otra sangre.

Arrastrándose -astilla y no bastón - recorre la acera una mendiga.

El corazón del daño vibra en cada segundo de la vida.

Seguir duele. Duele decir, escuchar o no haber dicho, duelen...

Este dolor referido al decir y al no haber dicho proponen un nuevo lugar de la enunciación, desde donde escribir se ha cargado de responsabilidad ética, ante el mundo representado, y trasciende los márgenes estéticos de lo que Villena ha institucionalizado, generacional y personalmente, como lo literario. Se nos explica, de este modo, la calificación de "antiliteratura" para el libro. Razón del libro y razón del cambio que Marginados experimenta con esta poesía, signo literario y gesto social.

\section{NOTAS}

1 Se pone a prueba tres supuestos básicos: el valor logo-céntrico del signo,la organización del discurso y la función del sujeto escritor como originador de todo significado textual.Objeta la confianza en la razón y en la inteligibilidad.(Derrida,Lacan, Barthes y Foucault).De este modo se cuestiona la autosuficiencia textual, los límites del texto se abren y la autoridad del escritor se viene abajo. La escritura importa más que el hablante implicado en el discurso. Las teorías postestructuralistas aparecen como un desafio a los supuestos del humanismo clásico y a la filosofla idealista que lo fundamentó. Critican los supuestos de la escritura realista tradicional en la que el hombre era origen de toda significación y controlaba la totalidad del texto y de los lenguajes usados en el discurso. Dentro del contexto del discurso realista se consideró al lenguaje como un instrumento transparente para transportar información sobre personajes y acontecimientos, como si se tratase de producir un idioma inocente, libre de implicancias ideológicas.

2 Lanz (1994) explica, en las antipodas de la crítica rupturista, que "no cabe duda de que hacia 1977 se inicia una etapa nueva en la poesía espafiola más joven, etapa que se extiende hasta la frontera de nuestros dfas y que parece empieza a decaer ahora en sus gustos y corrientes predominantes. Los hechos culturales se unen a los políticos para abrir un nuevo periodo en la historia de la poesía más reciente..." Esta es la delimitación que hace Lanz de la poesía que está entre los Novísimos y la actual Poesía de la Experiencia de Luis Garcia Montero, por ejemplo. "En consecuencia - dice Lanz- se pretendió ignorar los casi cuarenta ańos de dictadura que habla soportado el pais". "Desde esta perspectiva los novisimos se convertían, no en la primera generación literaria del postfranquismo, sino en la última que produjo la dictadura". Reconoce Lanz que situar a la poeśa novisima dentro o bajo la cultura franquista no es algo peyorativo, porque bajo 
el mismo signo tuvieron cabida manifestaciones claramente antifranquistas, como la poesla social. Pero lo que intenta delimitar es la fecha de inicio de la poesfa de la cultura postfranquista, el año 1977 dos años después de la muerte del dictador. Lanz concluye en que en los últimos años de los 70, confluye en esta tendencia de revisión culturalista de la tradición y la recuperación del yo, dos grupos de poetas: los posfranquistas que se inician y los novísimos que culminan su segunda etapa. De estas dos vertientes se deriva a la poesía a la "poesía de la experiencia figurada", "donde la historia de un personaje se presenta de ordinario como pura ficción". Si bien en esto se subraya la ficcionalidad, hay un acercamiento a la realidad en cuanto "experiencia releida de la realidad", con lo que se coincide una vez más con el punto de partida culturalista de los novísimos.

3 El nombre de poesia de la experiencia procede del título de un libro de Robert Langbaum, The poetry of experience (The dramatic monologue in modern literary tradition). Según Shirley Mangini, citada por J. L. Garcfa Martín (op. cit, 1992, p.200), "declara algo, no como una idea, sino como una experiencia de la que se pueden extraer las ideas". Gil de Biedma fue el divulgador en Espafía de las teorías de Langbaum y resumía esta poética con estas palabras: "El poema es, antes que nada, algo dicho por alguien en una determinada situación y en un cierto momento. Quién lo dice, a quién, dónde y cuándo y por qué, son ahora algo más que simples precisiones añadidas para dar a la representación literaria de los afectos humanos un viso de realidad: son los factores determinantes del poema, en su fondo y en su forma". Con frecuencia usa el monólogo dramático, el tono autobiográfico y confidencial, pero se trata de una falsa biografia, como en la novela picaresca, el yo del enunciado no se identifica con el del autor.

4 Esto es en el envío del poema Navios en Verano: "La alegría del lenguaje es nuestro único señor.I La alegría de la posesión nuestro único objeto".

\section{BIBLIOGRAFIA GENERAL}

BRINES, F. (1990) "Presentación de Luis Antonio de Villena" en Litoral, revista de la Poesía y el Pensamiento, Málaga.

GARCIA MARTIN, J. L. (1980), Las voces y los ecos, Júcar, Gijón, 1980.

- (1980), La poesía figurativa. Crónica parcial de quince afios de poesía espafíola, Renacimiento,Sevilla, 1992.

JIMENEZ, J. O. (1989) "Variedad y riqueza de una estética brillante", en Insula N. 0 505, Afio XIIV, Enero de 1989, pp. 1-2

(1987) "Reflexiones sobre los Postnovisimos" de Luis Antonio De Villena, en Insula, No:492.Año XIII.Nov.1987.p.9.

LANZ, JUAN JOSE, "Primera etapa de una generación. Notas para la definición de un espacio poético: 1977-1982", en Insula, 565, Afo XIIX, Enero de 1994, Madrid, p.3-6.

VILLENA, L. A. DE (1986), "Enlaces entre vanguardia y tradición" (Una aproximación a la estética novísima) en El estado de las poestas No: 3 de Los Cuadernos del Norte, Oviedo,Ed.La Caja de Ahorros de Asturias,

- (1988) Poesía 1970-1984, Visor, Madrid, (Prólogo de José Olivio Jiménez)

- (1990) Como a lugar extrafío, Madrid, Visor.

- (1993) Marginados, Madrid, Visor.

- (1992) El libro de las perversiones, Barcelona, Planeta.

- (1989) Luis A. de Villena, Málaga, Centro Cultural de la Generación del 27, 1989. 
- (1993) Los trabajos del ocio, Gijón, Libros del Pexe.

- (1986) Postnovisimos, Madrid, Visor,

- (1992) Fin de siglo, Madrid, Visor.

- (1989) Heterodoxias y Contraculturas (en colaboración con Fernando Savater), Barcelona, Montesinos.

- (1981) Un paganismo nuevo, Zaragoza, Olifante

- (1994) "El postismo en los días de Venecia" en Lateral/dic. 1994, Barcelona, págs. 21-26 